\title{
Experimental Evalutionof Tensile Strenght of Cryogenically Solidified Aluminium Based Metal Matrix Composites (MMC)
}

\author{
Kuwarmausam ${ }^{1}$, Prabal Pratap Singh ${ }^{2}$, Ankit Mishra ${ }^{3}$ \\ ${ }^{1}$ Department of Mechanical Engineering, GLA University, Mathura, India \\ ${ }^{2,3}$ Department of Chemistry, GLA University, Mathura, India \\ kuwar.mausasm@gla.ac.in ${ }^{1}$
}

Article History: Received: 10 November 2020; Revised: 12 January 2021; Accepted: 27 January 2021; Published online: 05 April 2021

\begin{abstract}
Present technology demanded high strength lightweight material which offers good mechanical property and light in weight. Metal matrix composite is one popular type of such material. In this research authors, aluminum is reinforced to increase its properties like hardness, strength, elastic stiffness to suits the needs to design. Aluminum of grade LM13, which is light material reinforced with boron carbide to improves mechanical properties like strength hardness and elastic properties. In this paper author experimentally evaluate the mechanical properties of Aluminium LM13. The weight percentage of boron carbide by varying with a range of 5\%,10\%,15\%, and 20\%. An improved property of MMC makes them useful in different areas like aerospace and automotive industries. The microstructure of developed material has been reported in this paper.

Keywords: Aluminium, Boron Carbide, MMC, Microstructure, mechanical properties Abbreviation, MMC: Metal matrix composite, SEM: Scanning Electron Microscopy
\end{abstract}

\section{Introduction}

In present, composite materials have effectively swapped the old-style materials in several light weight and high strength and stiffness applications. Sagar et al. [1]; Kumar et al. [2]; Janamatti and Rao [3] Composites having high strength, good toughness, better creep resistance and extremely hard to wear materials are useful in many industrious areas like automobile industries, aerospace industries and tools industries and so on. Daniel and Harish [4]; Prakash et al. [5] Two dissimilar materials with dissimilar physical or chemical properties, when they are joint on macroscopic scale they may have finest required properties over the individual materials is known as composite material.

Jayaprakash et al. [6] Stir casting is one simple, cost effective and useful method of various methods for the production of MMCs or AMCs or NMMCs.

Arunkumar et al. [7] Done an investigational approach on tensile and compression behaviour of al, silicon carbide, and graphitehybrid composite through and without cryogenic treatment

Hemanth et al. [8]; Hassan and Gupta [9] The regeneration of $\mathrm{Al}$ as a reinforcement component was conceived in the mid nineties because of environmental issues and structural rigidity andLevels of comfort. A big change in Al's assets Lightweight alloys have generated enormous demand for the car industry as fuel consumption has decreased.

Pandey et al. [10]; Mausam et al. [11] The methods used for manufacturing the various MMCs relies on parameters such as martial type and matrix composition and reinforcement, wettability, and the uniform distribution of the base and output matrix reinforcing particles. The manufacturing processes for aluminum-based composites were graded in two groups according to operating conditions: liquid-state manufacturing and solidstate manufacturing processes.

Arun and Swamy [12] MMCs based on aluminium have been used as a product in several different applications, such as motor cylinders, engine pistons yet many others. Specific efficiency and stiffness of the part reinforcement MMC also identified exceptional intrigues. pcm.

Nagar and Sharma [13] discuss discuss about nano particles based fatty acids and paraffin wax reinforced

Hassan et al. [14]; Rao et al. [15] Strength is not only main standards but also it must be lightweight because in aircraft and automobile industry the material with high strength and low weight is required. Now a days metal based composite play the role of back bone in numbers of area like material advancement, solar energy conversion, medical field, and many others. 


\section{Materials Used}

Aluminum Alloy LM13 is capable to withstand with higher temperature and loads. Such type of alloy mainly used in automotive sector for manufacturing component like piston where stresses are more and also alloy has good wear resistance. Table 1 reported composition of Aluminum LM13.

Table 1. Composition and weight \% of Aluminium LM13

\begin{tabular}{|l|l|}
\hline Composition of materials & $\mathrm{Wt} \%$ percentage \\
\hline Copper & $0.4-1.4$ \\
\hline Magnesium & $0.8-1.5$ \\
\hline Silicon & 11 \\
\hline Iron & 0.85 \\
\hline Manganese & 0.60 \\
\hline Nickel & $2.5-4$ \\
\hline Zinc & 0.15 \\
\hline Titanium & 0.25 \\
\hline
\end{tabular}

Boron carbide is one of the hardest synthetic material, ranking third behind cubic boron nitride and diamond. Boron Carbide is used as reinforcing material for aluminum in secure vests, bicycles and in numerous industrial applications. Figure 1 represent the boron carbide.

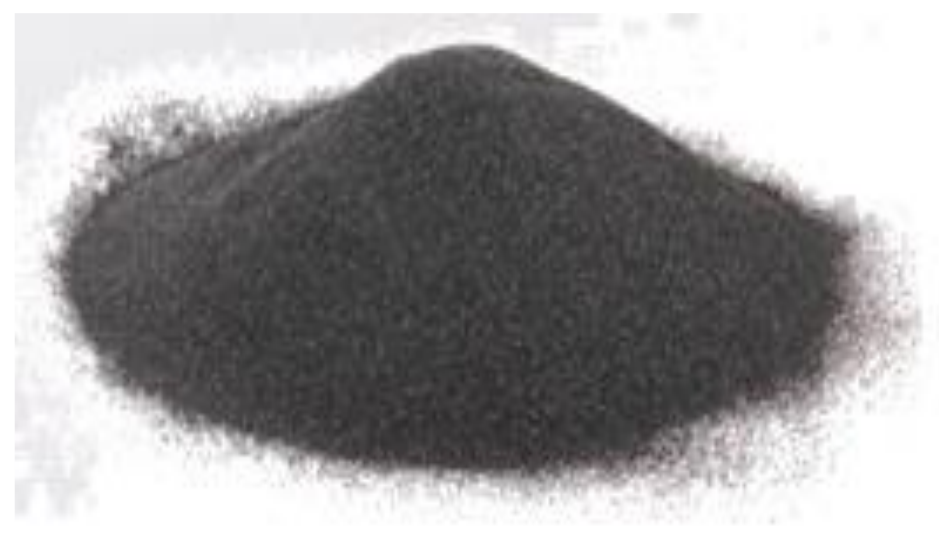

Figure 1. Boron Carbide

The chill box is fabricated using mild steel and brazed with different copper end chill thickness of $7 \mathrm{~mm}$, $14 \mathrm{~mm}, 18 \mathrm{~mm}$ and $25 \mathrm{~mm}$ respectively. The preparations are made to circulate liquid nitrogen to produce cryogenic effect during sand casting. Due to shrinkage problem cryogenically solidification is more effective and lump zones can be reduced in the sand moulds.

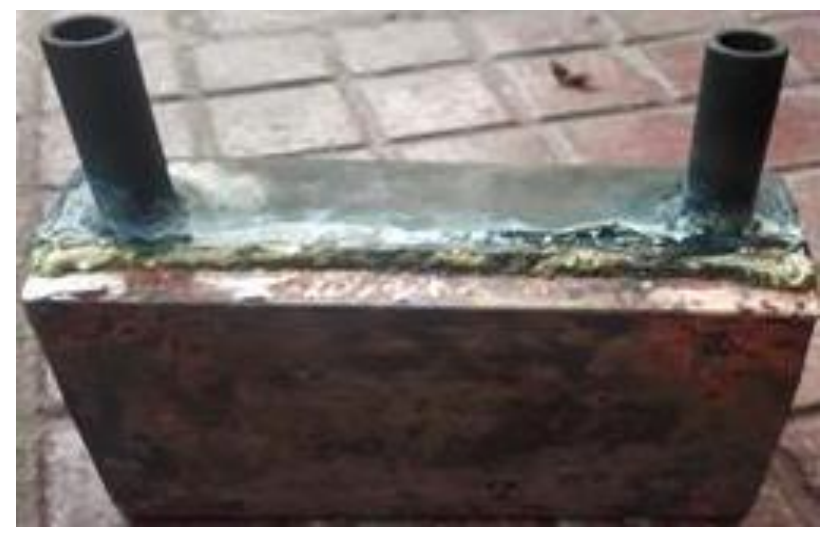

Figure 2. Chilling Box used in experiment 


\section{Preparation of MMC}

- The aluminium is weighed and cut into required size and placed in a crucible. Then crucible kept in a induction furnace and alloy is melted in furnace at temperature of $740 \mathrm{o} \mathrm{C}$.

- The Boron carbide was kept in a crucible then placed in a electric oven for preheating till 35 min about $3250 \mathrm{C}$.

- $\quad$ Both metal mixed and stirred by the use of manual stirrer to get uniform distribution of reinforcement.

- $\quad$ The composite casting was taken for machining operation for removing rough surfaces.

- The composite castings were compressed by hydraulic compression testing machine to remove blow holes (if any) and also to get perfect flatness on both sides of the cast parts.

\section{Test Specimen preparation}

The specimens were prepared based on ASTM standard test methods adopted for tension testing of sample specimen.

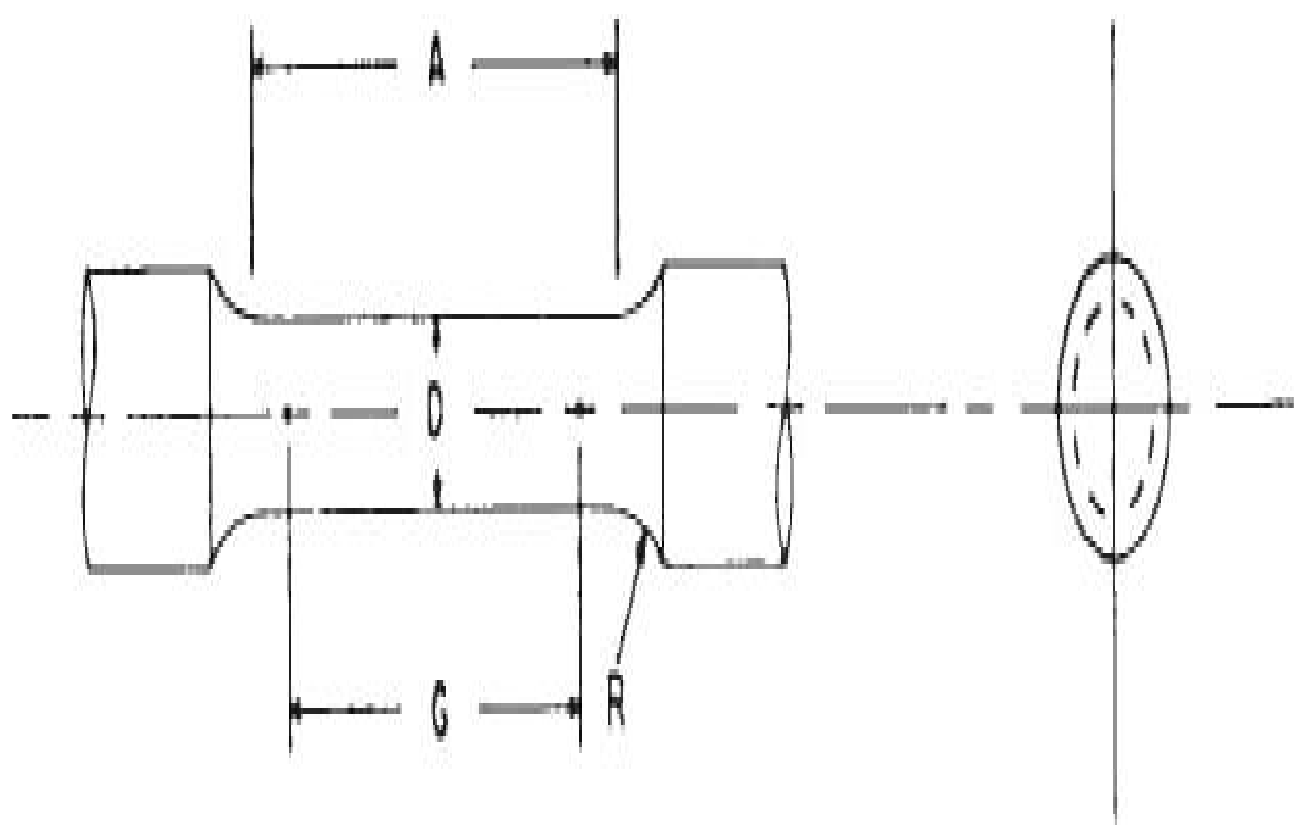

Figure 3. ASTM standard test specimen

\section{Results and discussion}

\subsection{Microstructure SEM Analysis}

Scanning Electron Microscopy (SEM) is a type of test process that scans a sample material with high-energy beam of electrons to obtain a magnified image for analysis. It is also known as SEM analysis. The SEM image shows the uniform distribution of particles in the matrix, good interfacial integrity between the matrix and reinforcement and also it shows presence of minimum porosity in devolved materials. 


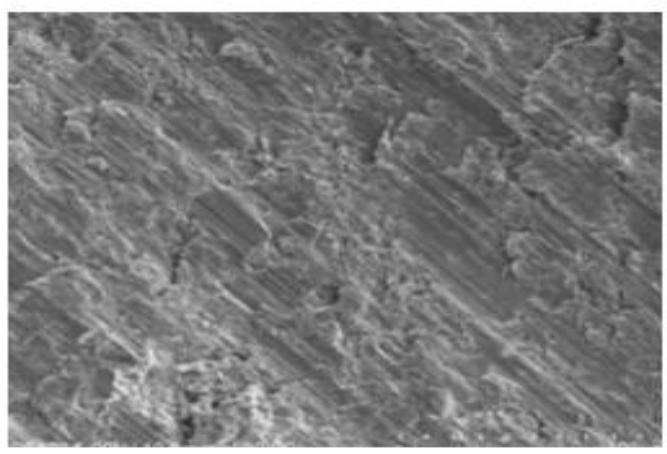

a. $5 \%$ reinforcement

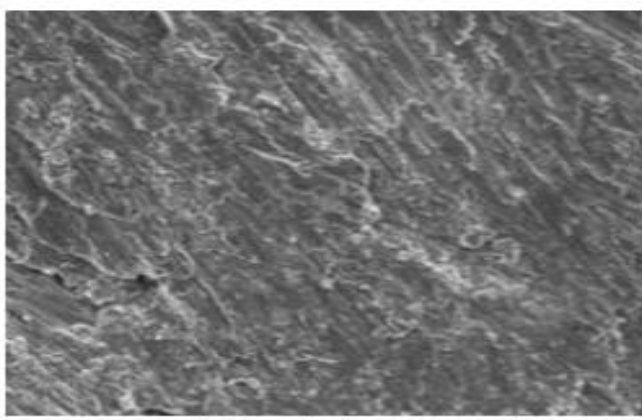

c. $15 \%$ reinforcement

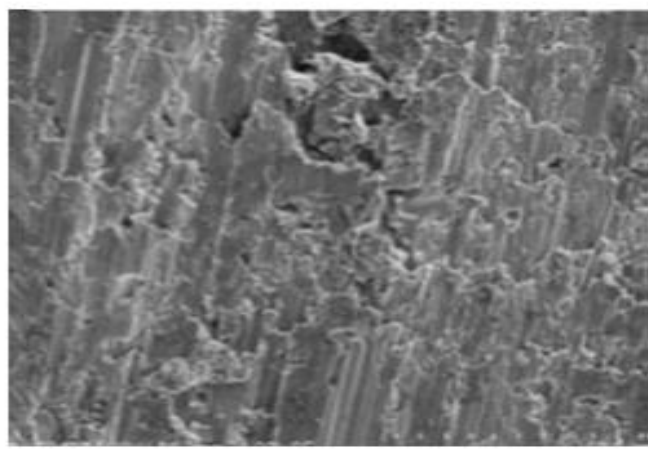

b. $10 \%$ reinforcement

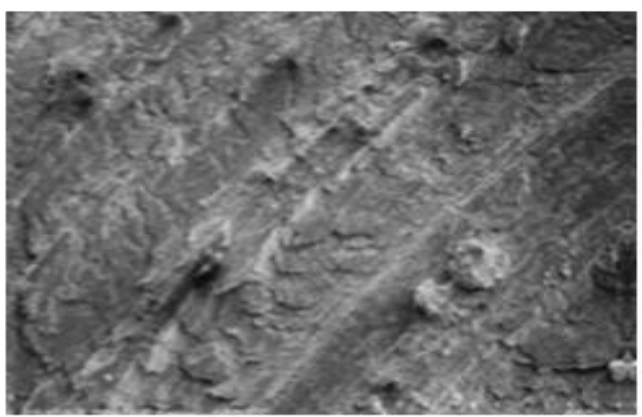

d. $20 \%$ reinforcement

Figure 4. Microstructure of reinforced MMC

\subsection{Hardness Test}

Hardness testing machine determines strength of the material by measuring its resistance to penetration, indentation and scratching. Application of this testing enables to evaluate properties of material like ductility, strength and wear resistance. Variation of hardness shown in the table 2.

Table 2. Hardness variation of MMC

\begin{tabular}{|l|l|l|l|l|}
\hline $\begin{array}{l}\text { Percentage of } \\
\text { Reinforcement }\end{array}$ & $\begin{array}{l}\text { VHN @ Chill } \\
\mathbf{5 m m}\end{array}$ & $\begin{array}{l}\text { VHN @ Chill } \\
\mathbf{1 0 m m}\end{array}$ & $\begin{array}{l}\text { VHN @ Chill } \\
\mathbf{1 5 m m}\end{array}$ & $\begin{array}{l}\text { VHN @ Chill } \\
\mathbf{2 0 m m}\end{array}$ \\
\hline Al-LM13 & 68 & 70 & 74 & 71 \\
\hline $5 \%$ & 92 & 101 & 106 & 121 \\
\hline $10 \%$ & 110 & 121 & 132 & 146 \\
\hline $15 \%$ & 131 & 129 & 151 & 172 \\
\hline $20 \%$ & 132 & 162 & 185 & 209 \\
\hline
\end{tabular}

From the above table, hardness has been increased by increasing the percentage of reinforcement from 5\% to $20 \%$. Ductility decreases as the hardness increases which lead to decreased in machinability of the part.

\subsection{Tensile strength Test}

Universal testing machine used to measure the tensile strength of sample material. Table 3 reported all the experimental data reported during experiments and figure 5 to 10 represent the variation of tensile strength.

Table 3. Tensile strength variation of MMC

\begin{tabular}{|l|l|l|l|l|l|}
\hline $\begin{array}{l}\text { Boron } \\
\text { carbide }\end{array}$ & $\begin{array}{l}\text { Tensile } \\
\text { strength } \\
@ 5 \mathrm{~mm} \text { Chill }\end{array}$ & $\begin{array}{l}\text { Tensile } \\
\text { strength } \\
\text { @ 10mm } \\
\text { Chill }\end{array}$ & $\begin{array}{l}\text { Tensile } \\
\text { strength } \\
@ 15 \mathrm{~mm} \text { Chill }\end{array}$ & $\begin{array}{l}\text { Tensile } \\
\text { strength } \\
\text { @20mm Chill }\end{array}$ & $\begin{array}{l}\text { Tensile } \\
\text { strength } \\
\text { @ 25mm } \\
\text { Chill }\end{array}$ \\
\hline 0 & 61.412 & 120.125 & 139.623 & 143.689 & 159.633 \\
\hline
\end{tabular}




\begin{tabular}{|l|l|l|l|l|l|}
\hline 5 & 67.561 & 143.425 & 147.965 & 152.698 & 185.632 \\
\hline 10 & 98.598 & 144.635 & 156.367 & 163.985 & 188.256 \\
\hline 15 & 122.152 & 144.962 & 164.963 & 174.632 & 214.632 \\
\hline 20 & 136.651 & 146.363 & 168.523 & 187.363 & 264.895 \\
\hline
\end{tabular}

The above table shows the variation of ultimate tensile strength with increased percentage of Boron carbide. Here alloy exhibits tensile strength of $62 \mathrm{MPa}$, as Boron carbide is reinforced the strength increased to $67 \mathrm{MPa}$. In each step of increased \% of Boron carbide the tensile strength rises to around 5-10 MPa. Due to increasing chill thickness results in decreasing cooling rate as a result the tensile strength increases.

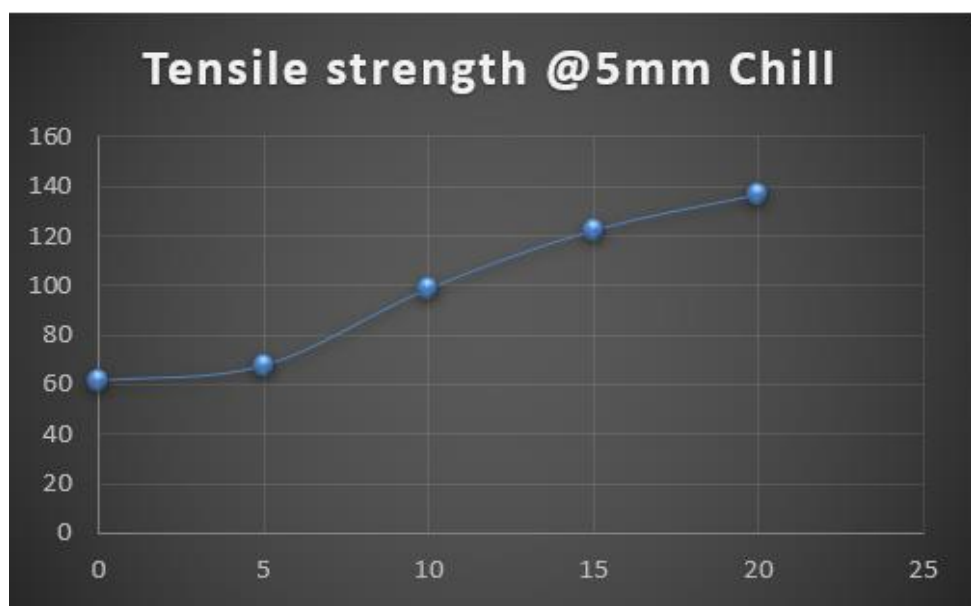

Figure 5. Tensile strength @ 5mm Chill

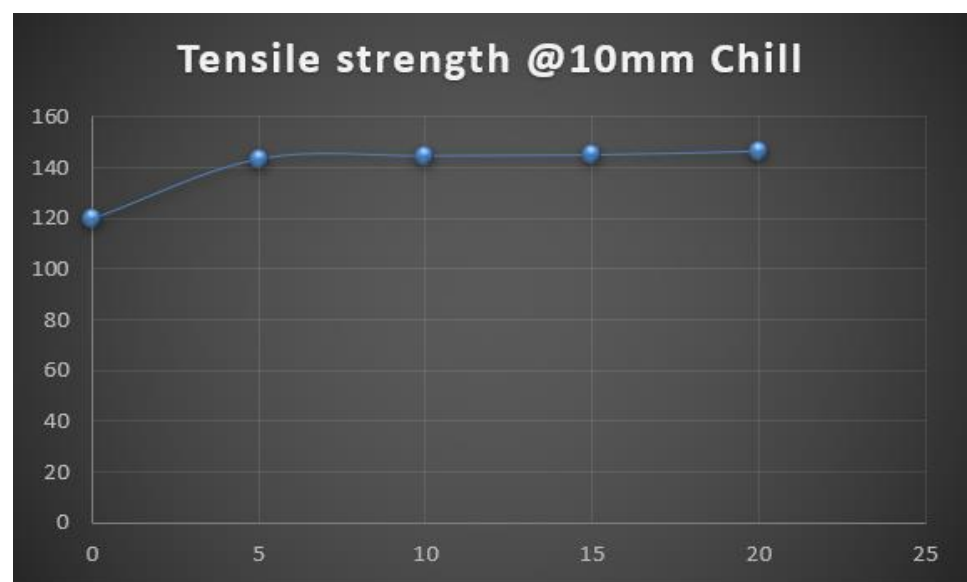

Figure 6. Tensile strength @ 10mm Chill

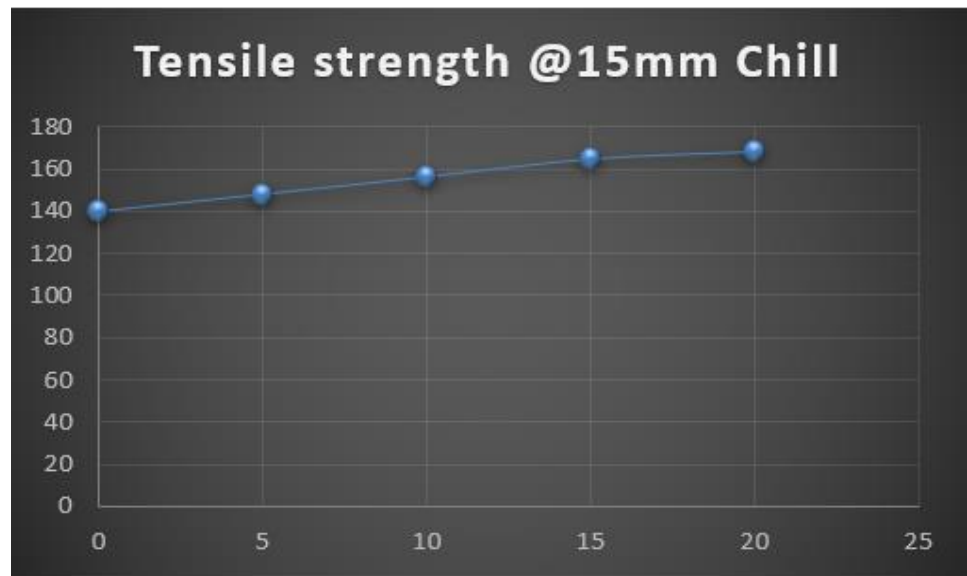

Figure 7. Tensile strength @ $15 \mathrm{~mm}$ Chill 


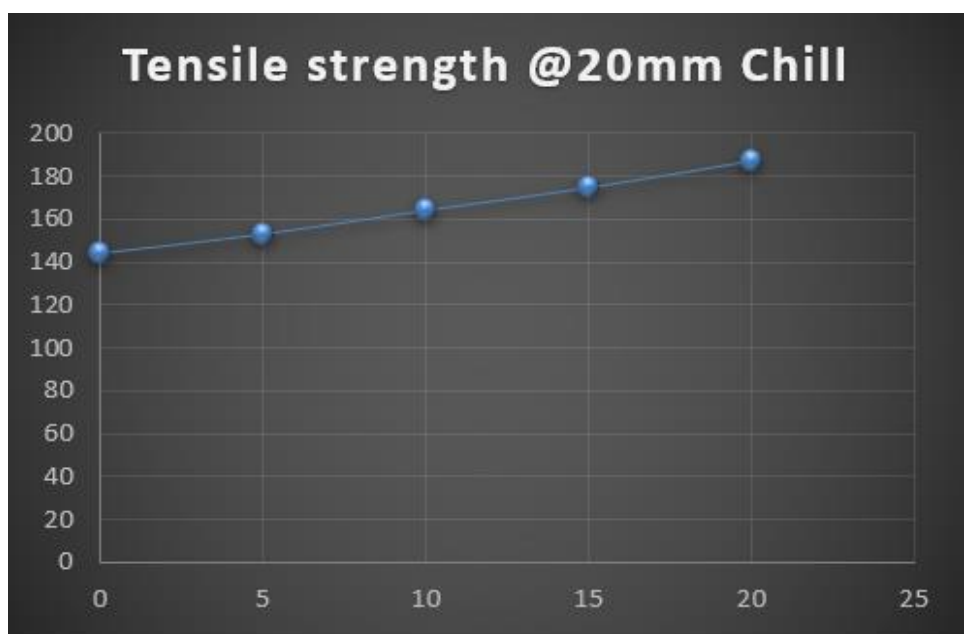

Figure 8. Tensile strength @20mm Chill

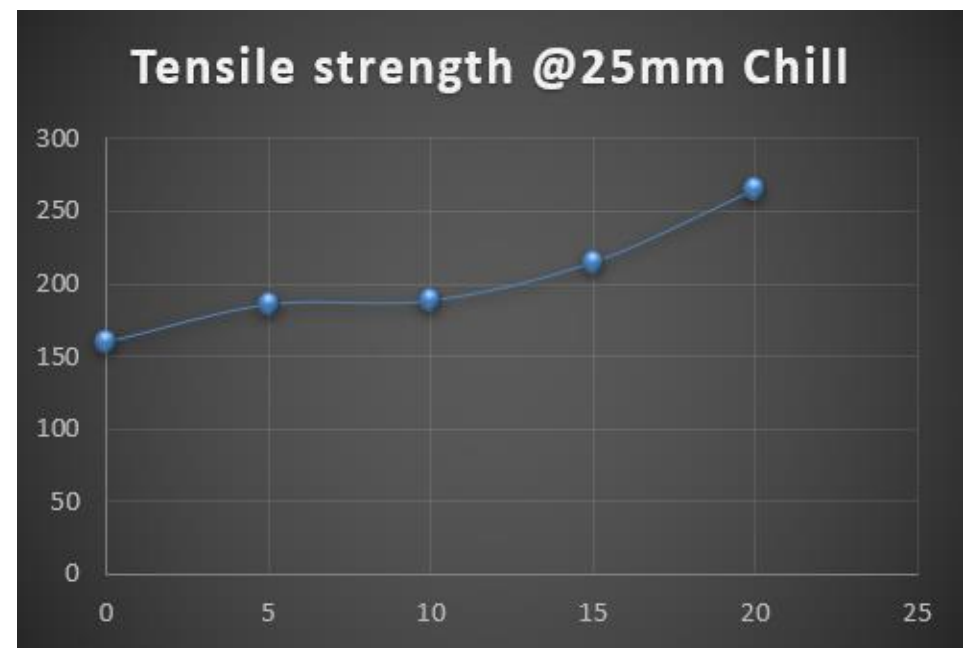

Figure 9. Tensile strength @ 25mm Chill

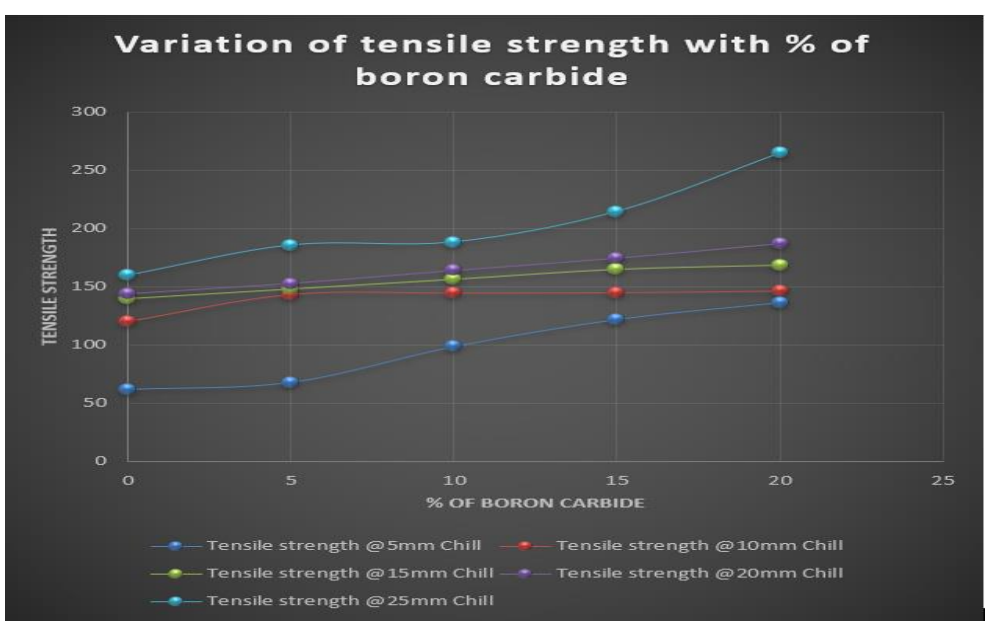

Figure10. Comparison of Tensile strength at different \% of Boron carbide and solidification rate.

\section{Closures}

MMC's were made-up by using sand casting technique and are cryogenically solidified using various chill thickness $5 \mathrm{~mm}, 10 \mathrm{~mm}, 15 \mathrm{~mm}, 20 \mathrm{~mm}$ and $25 \mathrm{~mm}$.

From the analysis of result the following conclusion are made. 
$>\quad$ The SEM image displays even distribution of boron carbide particles in the matrix alloy and shows good reinforcement.

$>$ Hardness has increased significantly with the increase content of boron carbide.

$>\quad$ Tensile strength increased gradually with increased quantity of boron carbide.

$>\quad$ The tensile strength and hardness of the cryogenically solidified MMC rises with growing the chilling thickness.

\section{References}

1. Sagar, C., T. Chandrashekar, and B. Tilak Chandra, "Effect of solutioninzing and Ageing on Hardness of Aluminum LM13-MgO particulate metal matrix composite", MS\&E, 2018. Vol.376, no.1, pp. 012084, 2018.

2. Kumar, S. A., Kumar, A. P., Naik, B. B., \& Ravi, B,. "A review on the mechanical properties of aluminum based metal matrix composites (MMCs"., International Journal. Engg. Sci. Invention, Vol.6, no.12, pp. 212-215, 2017.

3. Janamatti, S. V., Ganesh Rao, I. N., Rakesh, H., Manasa, T., \& Arul Mary, A. (2017). "Experimental Study on Mechanical Properties of LM6 Metal Matrix Composite with Ti-Boron Reinforcement", IRJET, ISSN, 2395, 0072, 2017.

4. Daniel, S., Harish, G., "A Study on the behaviour of Aluminium alloy (LM13) reinforced with Nano zro2 Particulate”, IOSR Journal of Engineering, Vol.4, no.2, pp.58-62, 2014.

5. Prakash, R.J,. "Fabrication and mechanical properties (strength \& hardness) of cryogenically solidified nano metal matrix composites", (CNMMC's), 2014.

6. Jayaprakash, R. H., Budan, A., \& Hemanth, J., "Preparation and Investigation on Properties of Cryogenically Solidified Nano Metal Matrix Composites”, International Journal of Engineering Research and Applications, Vol.4, pp.74-79, 2014.

7. Arunkumar, K.N., "An Experimental Investigation on Tensile and Compression behaviour ofaluminum, Silicon Carbide, and graphitehybrid Composite with and without Cryogenic Treatment", Materials Today: Proceedings, Vol.5, no.1, pp.904-910, 2018.

8. Hemanth, J,. "Development and property evaluation of aluminum alloy reinforced with nano- $\mathrm{ZrO} 2$ metal matrix composites (NMMCs)", Materials Science and Engineering, A, Vol.507, no.1-2, pp.110-113, 2009.

9. Hassan, S. F., M. Gupta. "Development of high strength magnesium based composites using elemental nickel particulates as reinforcement." Journal of Materials Science, Vol.37, no. 12, 2467-2474, 2002.

10. U. Pandey, R. Purohit, P. Agarwal, S. K. Dhakad, and R. S. Rana, "Effect of TiC particles on the mechanical properties of aluminium alloy metal matrix composites (MMCs)", Materials Today: Proceedings, Vol. 4, no. 4, pp. 5452-5460, 2017.

11. Mausam, K., Ghosh, S. K., kumar Tiwari, A., \& Singh, R. P., "Solar Power Development: A Root for Sustainable Development of India", IOP Conference Series:, Materials Science and Engineering, Vol. 691, no.1, pp. 012084, 2019.

12. Arun kumar M. B, R. P Swamy, "Evaluation of Mechanical properties of Al6061, fly ash and Eglass fiber reinforced Hybrid metal matrix composites,", ARPN Journal of Engineering and Applied Science, Vol. 6, no. 5, pp. 40-44, 2011.

13. Nagar, S. and K. Sharma, "Modern solar systems driven by nanoparticles-based fatty acids and paraffin wax phase change materials", Journal of Materials Science, pp. 1-26, 2020.

14. Hassan, S.F. and Gupta, M., "Effect of nano-zro2 particulates reinforcement on microstructure and mechanical behaviour of solidification processed elemental Mg"., Journal of composite materials, Vol. 41 no.21, pp.2533-2543, 2017.

15. Rao, C. P., Bhagyashekar, M. S., \& Viswanath, N., "Studies on Intermittent Facing of Metal Matrix Composites Using Cryogenic Treated Carbide Inserts", Procedia Engineering, Vol.97, pp.930-940, 2014 